\title{
Gonadotropin-Releasing Hormone Agonist Therapy and Obesity in Girls
}

\author{
Kobra Shiasi Arani ${ }^{1,} ;$ Fatemeh Heidari $^{2}$ \\ ${ }^{1}$ Department of Pediatric Endocrinology, Research Center for Biochemistry and Nutrition in Metabolic Disorders, Kashan University of Medical Sciences, Kashan, IR Iran \\ ${ }^{2}$ Nekoei-Hedayati Therapeutic Educational Center, Qom University of Medical Sciences, Qom, IR Iran \\ ${ }^{*}$ Corresponding author: Kobra Shiasi Arani, Department of Pediatric Endocrinology, Research Center for Biochemistry and Nutrition in Metabolic Disorders, Kashan University of \\ Medical Sciences, Kashan, IR Iran. Tel:+98-3155580190, Fax: +98-3155548900, E-mail: kobra.shiasi@yahoo.com
}

Received: September 2, 2014; Revised: March 3, 2015; Accepted: May 26, 2015

\begin{abstract}
Background: Depot preparations of gonadotropin-releasing hormone agonists (GnRHa) are the gold standard drugs for the treatment of central precocious puberty. A concern about these drugs is obesity.

Objectives:This study aimed to investigate the effect of gonadotropin-releasing hormone agonists (GnRHa) therapy on body mass index (BMI) in girls with central precocious puberty (CPP).

Patients and Methods: The girls with onset of puberty before eight years of age or menarche before nine years of age were studied. The weight, height, BMI, and pubertal stage were determined before and at sixth and 12th months of treatment. The GnRHa (Triptorelin) was administered intramuscularly for patients with rapidly progressive forms of CPP. Patients with slowly progressive forms of CPP were considered as control group.

Results: From 110 subjects with CPP, 46 girls (41.8\%) were considered as intervention and 64 (58.2\%) as control groups. The mean age at initial visit was $7.46 \pm 1.03$ years. The BMI standard deviation scores in both groups was not significantly different at sixth and 12 th months of treatment compared with baseline $(\mathrm{P}=0.257$ and $\mathrm{P}=0.839$, respectively). The prevalence of obesity was not significantly different between study groups at baseline and at and sixth and 12th months of therapy $(\mathrm{P}=0.11, \mathrm{P}=0.068$, and $\mathrm{P}=0.052$, respectively).

Conclusions: The GnRHa therapy has no effect on BMI and the prevalence of obesity.
\end{abstract}

Keywords: Gonadotropin-Releasing Hormone Agonist; Triptorelin; Puberty, Precocious; Obesity

\section{Background}

Precocious puberty in girls is defined as the appearance of secondary sexual characteristics before eight years or menarche before nine years of age. Central precocious puberty (CPP) is due to the premature activation of the hypothalamic-pituitary-gonadal axis. Precocious puberty may have significant physical and psychologic influence on affected patients and their parents. Increase in levels of sex steroid hormone may cause growth acceleration, advanced bone age, early menarche and impairment of final height. In a recent study, 3.2\% of girls younger than eight years had tanner stage 2 of breast development (1.3\% with normal weight and $12.1 \%$ of girls with body mass index (BMI) $\geq 85$ th percentile) (1). Mogensen et al. reported a significant increase in the number of patients with CPP over a 16-year period (2). This trend was also reported in Korean girls with CPP over a five-year period (3). Depot preparations of gonadotropin-releasing hormone agonists (GnRHa) are the gold standard drugs for the treatment of rapidly progressive forms of CPP (4). Depot forms of GnRHa continuously release the GnRH so desensitizes the gonadotropic cells of the pituitary gland to the endogenous GnRH and efficiently delay the progression of sexual puberty (5). A concern about these drugs is obesity. The experimental data are rather controversial, and there is no general agreement about the effect of GnRHa therapy on the prevalence of obesity and BMI in patients with CPP. Some of reported studies suggested an increase in BMI during GnRHa therapy (6-8). A study showed increase in total body fat, trunk fat mass, and insulin resistance in nine of 20 girls with idiopathic CPP treated with GnRHa (9). However, other data suggested that GnRHa therapy has no significant effect on weight excess in patients with CPP and a report suggested a reduction of BMI under gonadotropin-suppressive therapy (10-16).

\section{Objectives}

The aim of this prospective study was to investigate the effect of GnRHa therapy on BMI, BMI standard deviation scores (BMI-SDS), and the prevalence of obesity in girls with CPP in comparison with untreated patients.

\section{Patients and Methods}

The diagnosis of precocious puberty in girls was made based upon the onset of secondary sexual characteristics before eight or menarche before nine years of age. Patients were included in the study if CPP has been confirmed with clinical and laboratory criteria and

Copyright (C) 2015, Research Institute For Endocrine Sciences and Iran Endocrine Society. This is an open-access article distributed under the terms of the Creative Commons Attribution-NonCommercial 4.0 International License (http://creativecommons.org/licenses/by-nc/4.0/) which permits copy and redistribute the material just in noncommercial usages, provided the original work is properly cited. 
Shiasi Arani Ket al.

had good compliance with treatment strategy. Subjects with any additional conditions that might affect BMI (e.g. Cushing's syndrome, growth hormone deficiency, hypothyroidism, anorexia nervosa, dieting, and new exercise program) were excluded. The weight, height, BMI, and pubertal stage were measured at baseline and sixth and 12th month of treatment. The subjects were divided to three groups according to their BMI using the CDC (Centers for Disease Control and Prevention) growth charts: Obese, BMI $\geq 95$ th percentile for age and sex; Overweight, 85thpercentile $\leq$ BMI $\leq 95$ thpercentile for age and sex; and Normal weight, BMI $<85$ th percentile for age and sex (17). Height and BMI were expressed as SDS for chronological age and were calculated according to CDC growth data (17). Greulich-Pyle method was used for bone age determination and Bayley-Pinneau method for prediction of adult height $(18,19)$. MarshallTanner method was used for sexual maturation staging (20). Target Height was calculated by mean of parental heights minus 6.5. The hormonal criteria for the diagnosis of CPP were used on the basis of international recommendations (21-23). Magnetic resonance imaging (MRI) of the brain and hypothalamus-pituitary region was performed for patients with age of $\leq 6$ year at the onset of puberty.

The GnRHa (Triptorelin) was administered intramuscularly every 28 days at a dose of $3.75 \mathrm{mg}$ for the patients with rapidly progressive forms of CPP. Patients with slowly progressive forms of CPP and some patients that rejected treatment were considered as control group. This study design was approved by ethical committees of Kashan university of medical sciences, Kashan, Iran, and written informed consent was obtained from the parents of participants.

\subsection{Analysis}

Statistical analysis was performed using SPSS 16.0 (SPSS Inc, Chicago, Illinois, the United States). Values were presented as Mean \pm SD. $\mathrm{P}<0.05$ (two-sided) were considered statistically significant. The Mann-Whitney U test was used for determining differences between groups and the Friedman test was used to determine differences within each group.

\section{Results}

From 148 girls with CPP, 110 subjects met the inclusion criteria for study: 46 (41.8\%) considered as intervention group and 64 (58.2\%) as control group. General characteristic of two groups are shown in Table 1 . The mean age by initial visit was $7.46 \pm 1.03$ years $(7.89 \pm 1.15$ and $7.16 \pm 0.81$ years in intervention and control groups, respectively; $\mathrm{P}<0.0001$ ). The weight, BMI, and the prevalence of obesity and overweightness had no significant difference between study groups, but BMI-SDS was higher in control than in intervention group. The patients in intervention group had higher age and height than controls did, but height SDS was not different (Table 1). Moreover, the mean of target height was not significantly different between two groups (Table 1). The patients in intervention group had higher bone age and lower predicted adult height than control group did (Table 1). Bone age was $1.51 \pm 1.24$ years more than chronological age (1.75 \pm 1.02 and $1.34 \pm 1.46$ years in intervention and control groups, respectively; $\mathrm{P}=0.083)$. Basal luteinizing hormone $\mathrm{LH})$ level was $1.17 \pm 3.19 \mathrm{IU} / \mathrm{L}(0.87 \pm 0.79 \mathrm{IU} / \mathrm{L}$ and $1.5 \pm 4.3 \mathrm{IU} / \mathrm{L}$ in intervention and control groups, respectively; $\mathrm{P}=0.35)$. Basal follicular stimulating hormone (FSH) level was $2.43 \pm 1.97 \mathrm{IU} / \mathrm{L},(2.11 \pm 1.48 \mathrm{IU} / \mathrm{L}$ and $2.71 \pm 2.28 \mathrm{IU} / \mathrm{L}$ in intervention and control groups, respectively; $\mathrm{P}=0.26$ ).

\begin{tabular}{|c|c|c|c|c|}
\hline Variable & Total, $\mathbf{n}=110$ & Intervention Group, 46 Patients (41.8\%) & Control Group,64 Patients (58.2\%) & PValue \\
\hline Age, $y$ & $7.46 \pm 1.02$ & $7.89 \pm 1.16$ & $7.16 \pm 0.81$ & $<0.001$ \\
\hline Weight, kg & $31.6 \pm 7.48$ & $31.14 \pm 7.48$ & $31.93 \pm 7.53$ & 0.634 \\
\hline Height, cm & $127.49 \pm 7.56$ & $128.92 \pm 7.99$ & $126.47 \pm 7.12$ & 0.031 \\
\hline Height-SDS & $0.62 \pm 1$ & $0.45 \pm 0.94$ & $0.74 \pm 1.04$ & 0.224 \\
\hline Tall stature, $\%$ & 8.3 & 4.4 & 10.9 & 0.302 \\
\hline BMI, $\mathrm{kg} / \mathrm{m}^{2}$ & $19.28 \pm 3.47$ & $18.55 \pm 3.26$ & $19.8 \pm 3.55$ & 0.081 \\
\hline BMI-SDS & $1.22 \pm 1.31$ & $0.84 \pm 1.0$ & $1.49 \pm 1.29$ & 0.01 \\
\hline Obesity, \% & 38.5 & 28.9 & 45.3 & 0.11 \\
\hline Overweight, \% & 20.2 & 22.2 & 21.4 & 0.809 \\
\hline Bone age, y & $8.96 \pm 1.66$ & $9.66 \pm 1.70$ & $8.43 \pm 1.43$ & $<0.001$ \\
\hline PAH, $\mathrm{cm}$ & $156.31 \pm 7.61$ & $153.38 \pm 5.56$ & $158.57 \pm 8.34$ & $<0.001$ \\
\hline Target Height, cm & $158.06 \pm 4.75$ & $158.32 \pm 4.35$ & $157.75 \pm 8.34$ & 0.454 \\
\hline
\end{tabular}


Findings of brain MRI were normal in majority of patients. Other patients had abnormalities in brain MRI including microadenoma of hypophysis (two case), Chiari malformation type I (one case), fat deposition around hypophysis (one case), and prominent pineal gland (one case).

\subsection{Body Mass Index Changes During Gonadotro- pin-Releasing Hormone Agonist Therapy}

The weight of patients had increase significantly in intervention and control groups at sixth and12th months compared with the baseline values $(\mathrm{P}<0.0001)$ (Table 2 ). The height in both groups increased significantly ( $P$ $<0.0001)$. At baseline, the mean of height was higher in intervention group $(128.92 \pm 7.99 \mathrm{~cm})$ than in control group $(126.47 \pm 7.13 \mathrm{~cm})(\mathrm{P}=0.031)$; this difference persisted at the sixth month $(\mathrm{P}=0.015)$, but disappear in 12th month of treatment $(\mathrm{P}=0.18)$ (Table 2).The BMI increased significantly in intervention and control groups at sixth and 12th months compared with the baseline ( $\mathrm{P}<0.001)$. The BMI-SDS in intervention and control groups was not significantly different at sixth and 12th months compared with the baseline $(\mathrm{P}=0.26$ and $\mathrm{P}=0.84$, respectively). The difference in weight and BMI was not significant between intervention and control groups at baseline and at sixth and 12th months of therapy. However, BMI-SDS was significantly higher in intervention group than in control group at baseline $(P$ $=0.01)$ and at sixth month of therapy $(P=0.018)$, but not at 12th month of treatment $(P=0.051)$. The prevalence of obesity increased in controls and decreases in intervention group, but the difference was not significant ( $\mathrm{P}=$ 0.51 and $P=0.47$, respectively). The prevalence of obesity was not different between intervention and control groups at baseline and at sixth and 12th months of therapy $(\mathrm{P}=0.11, \mathrm{P}=0.07$, and $\mathrm{P}=0.052$, respectively) (Table $2)$. In addition, the prevalence of overweightness was not different between intervention and control groups baseline and at sixth and 12th months of therapy ( $\mathrm{P}=$ $0.81, \mathrm{P}=0.64$, and $\mathrm{P}=0.34$, respectively). The comparison of our results with other researches showed in Table 3.

Table 2. The Effects of Gonadotropin-Releasing Hormone Agonist Therapy on Body Mass Index During One-Year Follow-Up

\begin{tabular}{|c|c|c|c|c|}
\hline \multirow[t]{2}{*}{ Variable } & \multicolumn{3}{|c|}{ Time of Measurement } & \multirow[t]{2}{*}{ PValue } \\
\hline & Baseline & $6 \mathrm{mo}$ & $12 \mathrm{mo}$ & \\
\hline \multicolumn{5}{|l|}{ Weight, kg } \\
\hline Total & $31.6 \pm 7.49$ & $34.2 \pm 7.68$ & $36.53 \pm 8.53$ & $<0.0001$ \\
\hline Cases & $31.14 \pm 7.48$ & $34.05 \pm 7.53$ & $36.03 \pm 7.94$ & $<0.0001$ \\
\hline Controls & $31.92 \pm 7.84$ & $34.31 \pm 7.85$ & $36.98 \pm 9.08$ & $<0.0001$ \\
\hline \multicolumn{5}{|l|}{ Height, cm } \\
\hline Total & $127.49 \pm 7.56$ & $131.1 \pm 7.66$ & $134.44 \pm 7.99$ & $<0.0001$ \\
\hline Cases & $128.92 \pm 7.99$ & $133 \pm 7.66$ & $135.39 \pm 7.98$ & $<0.0001$ \\
\hline Controls & $126.47 \pm 7.13$ & $129.81 \pm 7.44$ & $133.59 \pm 7.99$ & $<0.0001$ \\
\hline \multicolumn{5}{|l|}{ BMI, $\mathrm{kg} / \mathrm{m}^{2}$} \\
\hline Total & $19.28 \pm 3.48$ & $19.75 \pm 3.56$ & $20.02 \pm 3.44$ & $<0.0001$ \\
\hline Cases & $18.55 \pm 3.26$ & $19.13 \pm 3.11$ & $19.47 \pm 2.96$ & $<0.0001$ \\
\hline Controls & $19.80 \pm 3.55$ & $20.2 \pm 3.48$ & $20.52 \pm 3.79$ & $<0.0001$ \\
\hline \multicolumn{5}{|l|}{ BMI-SDS } \\
\hline Total & $1.22 \pm 1.22$ & $1.19 \pm 1.03$ & $1.17 \pm 1.04$ & NS \\
\hline Cases & $0.84 \pm 1.01$ & $0.93 \pm 0.93$ & $0.92 \pm 0.82$ & NS \\
\hline Controls & $1.49 \pm 1.28$ & $1.42 \pm 1.06$ & $1.39 \pm 1.16$ & NS \\
\hline \multicolumn{5}{|c|}{ Obesity, n (\%) } \\
\hline Total & $42(38.5)$ & $42(41.2)$ & $33(36.3)$ & NS \\
\hline Cases & $13(28.9)$ & $14(30.4)$ & $11(25.6)$ & NS \\
\hline Controls & $29(45.3)$ & $28(50)$ & $22(45.8)$ & NS \\
\hline \multicolumn{5}{|c|}{ Overweightness, n (\%) } \\
\hline Total & $22(20.2)$ & $24(23.5)$ & $23(25.3)$ & NS \\
\hline Cases & $10(22.2)$ & $12(26.1)$ & $13(30.2)$ & NS \\
\hline Controls & $12(21.4)$ & $12(21.4)$ & $10(20.8)$ & NS \\
\hline
\end{tabular}


Table 3. Summary of Studies About the Changes of Body Mass Index Standard Deviation Score During Gonadotropin-Releasing Hormone Agonist Therapy in Girls a

\begin{tabular}{|c|c|c|c|c|c|}
\hline \multirow[t]{2}{*}{ Author (year), Reference } & \multirow[t]{2}{*}{ No } & \multicolumn{4}{|c|}{ Treatment BMI-SDS for CA } \\
\hline & & Baseline & Duration of Therapy, Mo & Final Visit & PValue \\
\hline \multicolumn{6}{|l|}{ Current study } \\
\hline Intervention group & 46 & $0.84 \pm 1.01$ & $0.92 \pm 0.82(12 \mathrm{mo})$ & $-\ldots$ & NS \\
\hline Control group & 64 & $1.49 \pm 1.28$ & $1.49 \pm 1.16(12 \mathrm{mo})$ & $\ldots$ & NS \\
\hline \multicolumn{6}{|l|}{ Arrigo (2004) } \\
\hline Intervention group & 101 & $1.39 \pm 1.07$ & $0.61 \pm 0.79(12 \mathrm{mo})$ & $0.11 \pm 0.52$ & $<0.001$ \\
\hline Control group & & & & & No control group \\
\hline \multicolumn{6}{|l|}{ Yuan (2011) } \\
\hline Intervention group & 57 & $0.35 \pm 0.79$ & $0.49 \pm 0.72(12 \mathrm{mo})$ & $-0.12 \pm 0.58$ & 0.03 \\
\hline Control group & 77 & $0.39 \pm 0.89$ & -_- & $0.29 \pm 0.94$ & NA \\
\hline \multicolumn{6}{|l|}{ Lee (2012) } \\
\hline Intervention group & 38 & $0.58 \pm 1.18$ & $0.79 \pm 0.84(12 \mathrm{mo})$ & $0.96 \pm 0.83$ & $<0.05$ \\
\hline Control group & & & & & No control group \\
\hline \multicolumn{6}{|l|}{ Traggiai (2005) } \\
\hline Intervention group & 29 & 1.7 & $1.8(12 \mathrm{mo})$ & 1.6 & NR \\
\hline Control group & 45 & 2.1 & $1.6(12 \mathrm{mo})$ & 1 & NR \\
\hline \multicolumn{6}{|l|}{ Poomthavorn (2011) } \\
\hline Intervention group & 47 & $1.26 \pm 0.95$ & NR & $0.16 \pm 1$ & NA \\
\hline Control group & 11 & NA & & & \\
\hline \multicolumn{6}{|l|}{ Oostdijk(1996) } \\
\hline Intervention group & 30 & 1.7 & $1.824 \mathrm{mo}$ & 1.44 & NS \\
\hline Control group & & & & & No control group \\
\hline \multicolumn{6}{|l|}{ Palmert (1999) } \\
\hline Intervention group & 96 & $1.1 \pm 0.1$ & $0.9 \pm 0.136 \mathrm{mo}$ & $0.9 \pm 0.1$ & NS \\
\hline Control group & & & & & No control group \\
\hline
\end{tabular}

a Abbreviations: BMI-SDS for CA, body mass index standard deviation score for chronological age; NA, not available; NS, not significant.

\section{Discussion}

\subsection{Obesity and Central Precocious Puberty in Girls}

The prevalence of obesity is progressively increasing worldwide; therefore, any treatment that aggravates obesity is undesirable. One frequently asked question from pediatric endocrinologists is the risk of obesity during GnRHa therapy. At present, a few studies have been performed to answer this question. Some studies have been compared the body composition of patients before and after discontinuation of treatment; in addition, because of long duration of therapy (mean, 5-6 years), several factors may affect body composition. We performed a clinical trial to assess changes in weight, height, and BMI in 110 girls with CPP that occur during first year of GnRHa therapy. In this study, the prevalence of obesity and overweightness in girls with CPP was higher from that reported worldwide and in Iranian children. In a systematic review and metaanalysis, the overall prevalence of obesity and overweight- ness in Iranian children were estimated to be about 5.1\% and $10.8 \%$, respectively (24). The prevalence of obesity and overweightness in our study was $38.5 \%$ and $20.2 \%$, respectively. Similar result was seen by Palmert et al. in patients with CPP ( $48 \%$ and $26 \%$ with BMI-SDS of over 85 th percentile and over 95th percentile, respectively), Glab et al. (9.8\% of children had BMI-SDS between 90th and 97th percentile and $22.0 \%$ above 97 th percentile) and Arrigo et al. (23.8\% of children had BMI-SDS $\geq 2)(10,11,16)$. Our data also indicate that the prevalence of obesity in girls with slowly progressive form of CPP is not different from rapidly progressive forms. Other important finding in this study was no difference in the prevalence of obesity and overweightness during treatment or follow-up in intervention and control groups. Similar results were achieved by some researchers $(10,11,13)$. Only one research reported the reduction of prevalence of obesity and overweightness during GnRHa therapy after an average follow-up of 44 months (16). 


\subsection{Body Mass Index Standard Changes During} Gonadotropin-Releasing Hormone Agonist Therapy

The experimental data are rather controversial and there is no general agreement on BMI changes during GnRHa therapy. In this study, we compared the patients that received treatment with the patients that rejected receiving drug or had slowly progressive form of CPP and therefore, no indication of treatment as control group. Most similar studies had not control group. Approximately, $60 \%$ of our patients had criteria for being overweight or obese at the baseline, and similar percentages were overweight or obese at the end of study. The BMI increased significantly in both intervention and control groups compared with baseline; however, BMI-SDS did not change significantly in both groups during study. The increase in BMI naturally occurs throughout childhood and no increase in BMI-SDS means that intervention had no effect on incidence of obesity. Thus, GnRHa therapy did not seem to be a risk factor for obesity in girls with CPP. These finding are in agreement with previous studies $(10,11,25,26)$ (Table 3$)$.

In a study by Gillis et al. 34 girls with CPP treated with a GnRHa (23 with monthly injections of triptorelin depot and 11 with histrelin implant) were evaluated before, and the end of treatment until menarche. Changes of BMI-SDS was not significant in neither group (26). Historically, Boot et al. have performed dual-energy x-ray absorptiometry (DEXA) before and during treatment with GnRHa in girls with CPP and early puberty. Their findings showed that BMI-SDS, fat mass, and percent of body fat for chronological age increased during GnRHa therapy (27). The recent study by Karamizadeh et al. on 30 non-obese female with idiopathic CPP showed that GnRHa therapy does not cause metabolic syndrome, but it may cause central obesity and hyperlipidemia (7). Tascilar et al. investigated the changes in body composition and insulin resistance in 20 girls with idiopathic CPP and reported moderate increase in total body fat, increase in trunk fat mass, and insulin resistance, and an insignificant slight increase in BMI (9). This study had not control group; also they had not reported BMISDS changes in their patients. We cannot evaluate these parameters in our patients. On the other hand, Ko et al. assessed percentage of body fat with DEXA method, at baseline and after one year of GnRHa therapy in 121 Korean girls and concluded that GnRHa therapy does not increase the prevalence of obesity in girls with CPP (13). Previously, these authors had reported an increase in BMI-SDS during GnRHa treatment in 38 Korean girls with CPP (8). One of the researches that had similar method to our study was the one performed by Yuan et al. (Table 3). They observed a slight increase in BMISDS at the end of treatment in comparison with control group, but both cases and controls at near adult height had BMI-SDS of lower than baseline without significant difference at baseline and at the end of study (12). Only one report has shown the reduction of BMI-SDS and obesity prevalence (from $4 \%$ to $0 \%$ ) under GnRHa therapy in girls with idiopathic CPP (16). Similar to our patients, their patients had high prevalence of obesity at baseline, and the authors did not mention the change in exercise or diet habit of these patients. Traggiai, et al. reviewed BMI-SDS changes in 29 female patients with idiopathic CPP during GnRHa therapy compared with 45 healthy girls with normal puberty. Mean BMI-SDS increased in girls with idiopathic CPP during therapy, but 2.5 years after the end of therapy, the values were not different from baseline. On the other hand, mean BMI-SDS, decreased in girls with normal puberty. This difference was attributed to the treatment (6). In this study control group had not CPP and was not a good candidate for intervention. In other study, mean BMI zscore of $47 \mathrm{GnRHa}$-treated girls with idiopathic CPP was 1.26 at baseline and 0.16 at the time of reaching adult height (15).

\section{Acknowledgements}

The authors would like to thank the Kashan University of Medical Sciences, for their support; this study was extracted from a research proposal (No. 9122) in Department of Pediatric Endocrinology.

\section{Authors' Contributions}

Study concept and design: Kobra Shiasi Arani. Acquisition of data: Kobra Shiasi Arani and Fatemeh Heidari. Analysis and interpretation of data, drafting of manuscript, critical revision of the manuscript for important intellectual content, statistical analysis, administrative, technical, and material support, and study supervision: Kobra Shiasi Arani.

\section{Funding/Support}

This study was supported by Kashan University of Medical Sciences, Kashan, Iran.

\section{References}

1. Rosenfield RL, Lipton RB, Drum ML. Thelarche, pubarche, and menarche attainment in children with normal and elevated body mass index. Pediatrics. 2009;123(1):84-8.

2. Mogensen SS, Aksglaede L, Mouritsen A, Sorensen K, Main KM, Gideon P, et al. Diagnostic work-up of 449 consecutive girls who were referred to be evaluated for precocious puberty. J Clin Endocrinol Metab. 2011;96(5):1393-401.

3. Kim HK, Kee SJ, Seo JY, Yang EM, Chae HJ, Kim CJ. Gonadotropinreleasing hormone stimulation test for precocious puberty. Korean J Lab Med. 2011;31(4):244-9.

4. Fuqua JS. Treatment and outcomes of precocious puberty: an update. JClin Endocrinol Metab. 2013;98(6):2198-207.

5. Ságodi L, Sólyom E, Lomb ay B, Almási A, Vámosi I. The effect of gonadotropin releasing hormone analogue therapy in girls with idiopathic central precocious puberty. Orvosi Hetilap. 2012;153(11):418-24.

6. Traggiai C, Perucchin PP, Zerbini K, Gastaldi R, De Biasio P, Lorini R. Outcome after depot gonadotrophin-releasing hormone agonist treatment for central precocious puberty: effects on body mass index and final height. Eur J Endocrinol. 2005;153(3):463. 
7. Karamizadeh Z, Tabebordbar M, Saki F, Karamifar H, Amirhakimi $\mathrm{G}$. The side effects of gonadotropin releasing hormone analog (diphereline) in treatment of idiopathic central precocious puberty. Acta Med Iran. 2013;51(1):41-6.

8. Lee SJ, Yang EM, Seo JY, Kim CJ. Effects of gonadotropin-releasing hormone agonist therapy on body mass index and height in girls with central precocious puberty. Chonnam Med J. 2012;48(1):27-31.

9. Tascilar ME, Bilir P, Akinci A, Kose K, Akcora D, Inceoglu D, et al. The effect of gonadotropin-releasing hormone analog treatment (leuprolide) on body fat distribution in idiopathic central precocious puberty. TurkJ Pediatr. 2011;53(1):27-33.

10. Palmert MR, Mansfield MJ, Crowley WJ, Crigler JJ, Crawford JD, Boepple PA. Is obesity an outcome of gonadotropin-releasing hormone agonist administration? Analysis of growth and body composition in 110 patients with central precocious puberty. $J$ Clin Endocrinol Metab. 1999;84(12):4480-8.

11. Glab E, Barg E, Wikiera B, Grabowski M, Noczynska A. Influence of GnRH analog therapy on body mass in central precocious puberty. Pediatr Endocrinol Diabetes Metab. 2009;15(1):7-11.

12. Yuan JN, Liang L, Cai XD, Li Z, Bai M, Gu CP. [Impact of gonadotropin-releasing hormone analogs on body mass index in girls with idiopathic central precocious puberty: a long-term follow-up study]. Zhongguo Dang Dai Er Ke Za Zhi. 2011;13(11):896-9.

13. Ko JH, Lee HS, Lim JS, Kim SM, Hwang JS. Changes in bone mineral density and body composition in children with central precocious puberty and early puberty before and after one year of treatment with GnRH agonist. Horm Res Paediatr. 2011;75(3):174-9.

14. Park HK, Lee HS, Ko JH, Hwang IT, Lim JS, Hwang JS. The effect of gonadotrophin-releasing hormone agonist treatment over 3 years on bone mineral density and body composition in girls with central precocious puberty. Clin Endocrinol (Oxf). 2012;77(5):743-8.

15. Poomthavorn P, Suphasit R, Mahachoklertwattana P. Adult height, body mass index and time of menarche of girls with idiopathic central precocious puberty after gonadotropin-releasing hormone analogue treatment. Gynecol Endocrinol. 2011;27(8):524-8.

16. Arrigo T, De Luca F, Antoniazzi F, Galluzzi F, Segni M, Rosano M, et al. Reduction of baseline body mass index under gonadotropinsuppressive therapy in girls with idiopathic precocious puberty.
European journal of endocrinology. 2004;150(4):533-7.

17. centers for disease control and prevention. Using the BMI-for-Age Growth Charts. 2009. Available from: http://www.cdc.gov/nccdphp/dnpa/growthcharts/training/modules/module1/text/module1print.pdf.

18. Paxton ML, Lamont AC, Stillwell AP. The reliability of the GreulichPyle method in bone age determination among Australian children. J Med Imaging Radiat Oncol. 2013;57(1):21-4.

19. Bar A, Linder B, Sobel EH, Saenger P, DiMartino-Nardi J. BayleyPinneau method of height prediction in girls with central precocious puberty: correlation with adult height. $J$ Pediatr. 1995;126(6):955-8.

20. Marshall WA, Tanner JM. Variations in pattern of pubertal changes in girls. Arch Dis Child.1969;44(235):291-303.

21. Wang ZF, Li GJ. [Value evaluation of follicle stimulating hormone and luteinizing hormone in the diagnosis of precocious puberty in girls by ROC curve analysis]. Zhongguo Dang Dai Er Ke Za Zhi. 2012;14(6):441-4.

22. Soriano-Guillén L, Argente J, editors. [Central precocious puberty: epidemiology, etiology, diagnosis and treatment].; Anales de pediatria (Barcelona, Spain: 2003).; 2011; pp. 336. e1-336. e13.

23. Liang JT. [Value of basal serum gonadotropin levels in the diagnosis of precocious puberty in girls]. Zhongguo Dang Dai Er Ke Za Zhi. 2012;14(12):942-5.

24. Feuillan PP, Jones JV, Barnes K, Klein KO, Cutler GJ. Follow-up of children and young adults after GnRH-agonist therapy or central precocious puberty. J Endocrinol Invest. 2001;24(9):734-6.

25. Oostdijk W, Rikken B, Schreuder S, Otten B, Odink R, Rouwe C, et al. Final height in central precocious puberty after long term treatment with a slow release GnRH agonist. Arch Dis Child. 1996;75(4):292-7.

26. Gillis D, Karavani G, Hirsch HJ, Strich D. Time to menarche and final height after histrelin implant treatment for central precocious puberty.J Pediatr. 2013;163(2):532-6.

27. Boot AM, Keizer-Schrama SMPFM, Pols HAP, Krenning EP, Drop SLS. Bone Mineral Density and Body Composition before and during Treatment with Gonadotropin-Releasing Hormone Agonist in Children with Central Precocious and Early Puberty $1 . J$ Clin Endocrinol Metabol. 1998;83(2):370-3. 